\title{
Theoretical Evaluation of Antioxidant Activity of Tea Catechins
}

\author{
N.S. Labidi ${ }^{1 *}$, L. Guerguer ${ }^{1}$, A. Kacemi ${ }^{1}$ \\ 1. Institut des Sciences, Département des Sciences de la Matière, \\ Centre Universitaire de Tamanrasset, BP (10034) Sersouf-Tamanrasset (11000)-Algeria
}

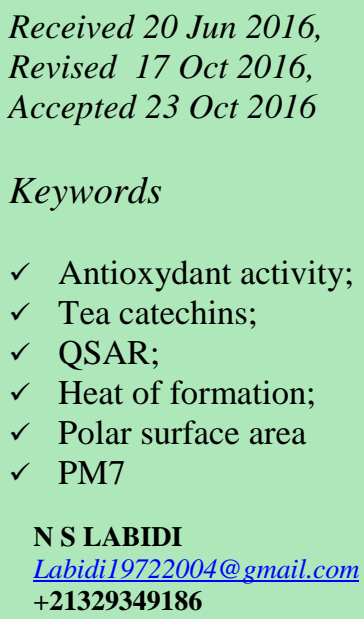

Received 20 Jun 2016,

Revised 17 Oct 2016 ,

Accepted 23 Oct 2016

Keywords

$\checkmark$ Antioxydant activity;

$\checkmark$ Tea catechins;

$\checkmark$ QSAR;

$\checkmark$ Heat of formation;

$\checkmark$ Polar surface area

$\checkmark$ PM7

N S LABIDI

Labidi19722004@gmail.com

$+21329349186$

\begin{abstract}
To quickly evaluate the antioxidant activity of tea catechins epicatechin (EC), epigallocatechin (EGC), epicatechingallate (ECG) and epigallocatechinsgallate (EGCG), a semi empiric quantum chemistry calculation methods were employed to calculate many parameters, such as molecular geometry, heat of formation $\left(\Delta_{\mathrm{f}} \mathrm{H}\right)$, pKa, Mulliken charges, electrostatic potential, bond dissociation enthalpy $\left(\Delta_{d} H\right)$, orbital's energy difference $\left(E_{\text {gap }}\right)$, Ovality, polarizability and polar surface area (PSA). Among calculated parameters only heat of formation $\left(\Delta_{\mathrm{f}} \mathrm{H}\right)$, bond dissociation energy $\left(\Delta_{\mathrm{d}} \mathrm{H}\right)$ and polar surface area (PSA) were correlated well with the antioxidant activity TEAC and DPPH values and give excellent correlation coefficients of $0.95,0.98$ and 0.94 successively. The results of such cheaper calculations can suitably scaled for predictive purpose.
\end{abstract}

\section{Introduction}

Tea is grown in more than 30 countries and is the most consumed drink in the world after water [1]. Tea is one of the richest sources of flavonoids, which in this product account for $90 \%$ of flavan-3-ols (catechins), in green tea, mainly monomeric catechins (colorless, water-soluble and astringent), most of which are epicatechin esterified with gallic acid [2]. Structural change of tea catechins during fermentation is strongly correlated with sensory qualities, such as color, taste and smell [3]. Tea leaves also contain appreciable amounts of biologically active compound which exhibit higher antioxidant properties and give the tea its astringent taste. Regular consumption of tea could thus provide protection against several types of cancers and reduce the risk of cardiovascular diseases or other types of diseases through the activity of these compounds [4].

The use of quantum chemical calculations to estimate antioxidants activities in agreement with experimental results is a big deal for computational chemists, especially for tea catechins, large size systems require high computational cost, especially to perform Møller-Plesset (MP), Coupled-Cluster (CC), or multiconfigurational self consistent field (MCSCF) calculations. On the other hand, Hartree-Fock (HF) and density functional theory (DFT) calculations fail drastically when performing field-response calculations [5-8]. Semi empirical methods differ from the more rigorous $\mathrm{Ab}$ initio methods in that most of the computationally intensive, that is, timeconsuming, parts of Hartree Fock theory have been replaced by approximations that have adjustable parameters, and these parameters are then adjusted so that the resulting method gives an optimized root mean square fit to a set of reference data. In addition to a quantum mechanical self-consistent field (SCF) procedure, semiempirical methods such as PM6 and PM7 are augmented by a small number of post-SCF modifications which are designed to improve the intermolecular interactions. Semi empirical methods have been extensively validated for properties such as heats of formation $\left(\Delta_{\mathrm{f}} \mathrm{H}\right)$, geometries and the energies of intermolecular interactions by comparison of reference data. QSAR/QSPR models based on semiempirical descriptors are of similar quality to DFT-based models and constitute a good compromise between accuracy and computational costs [9-16].

The aim of this work is to use the low cost computational methods, especially semiempirical (SE) methodologies to estimate the quantitative structure-activity relationship (QSAR) of tea catechins and to correlate them with the experimental trolox equivalent antioxidant capacity (TEAC) and (DPPH) free radical 
scavenging capacities parameters found in the literature. Three models have been obtained using calculated parameters such as the heat of formation $\left(\Delta_{\mathrm{f}} \mathrm{H}\right)$, bond dissociation energy $\left(\Delta_{\mathrm{d}} \mathrm{H}\right)$ of hydroxyl groups $(\mathrm{O}-\mathrm{H})$ and polar surface area (PSA). These models can be used to estimate the antioxidant activities of the new phenolic compounds derivatives.

\section{Computational details}

Catechins structures (Figure 1) were optimized using the functional density theory DFT at B3LYP exchange correlation and the $6-31+\mathrm{G}^{*}$ base set. The constraint imposed to the system is that the residual forces are less than $10^{-5}$ a.u. (Tight) using Gaussian 09 [17]. The semi-empirical calculations AM1 (Austin Model 1), PM3 (Parametric method 3), PM6 (Parametric method 6) and PM7 were performed with MOPAC 2012 [16, 18]. Molecular volume is calculated for optimized structures by the MM+ force field using HyperChem v8 [19]. Ovality, polarizability and polar surface area (PSA) were carried out using the QSAR of ChemBio3D-Ultra [20].

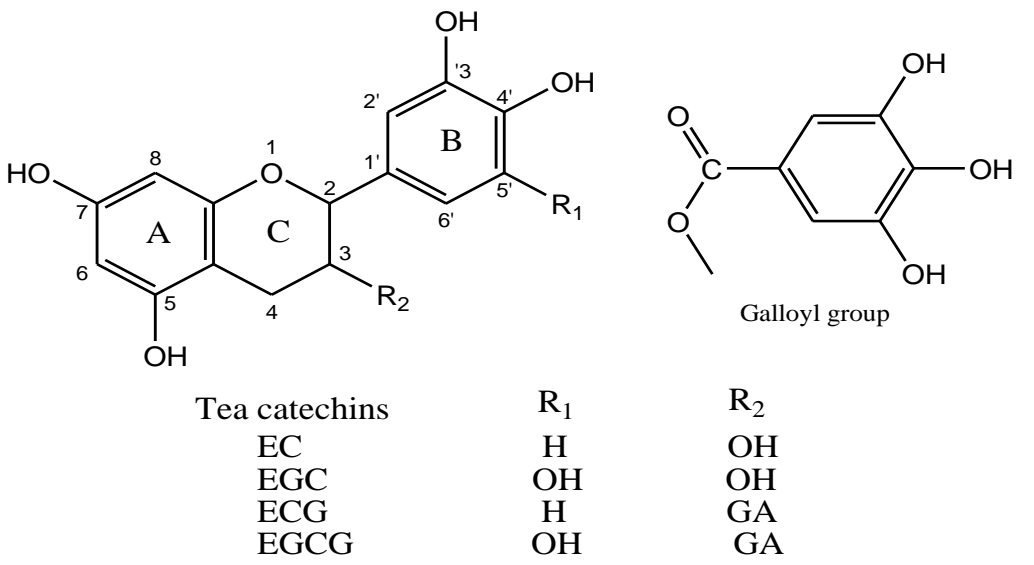

Figure 1: Structures of the tea catechins.

\section{Results and Discussion}

\subsection{Structural Properties}

The optimized molecular geometry of catechin is displayed in Figure 2.The selected bond lengths, bond angles and torsions angles are compared with X-ray data in Table 1. Figure 2 indicates that the interatomic distances and angles do not reveal any exception to the standard values.

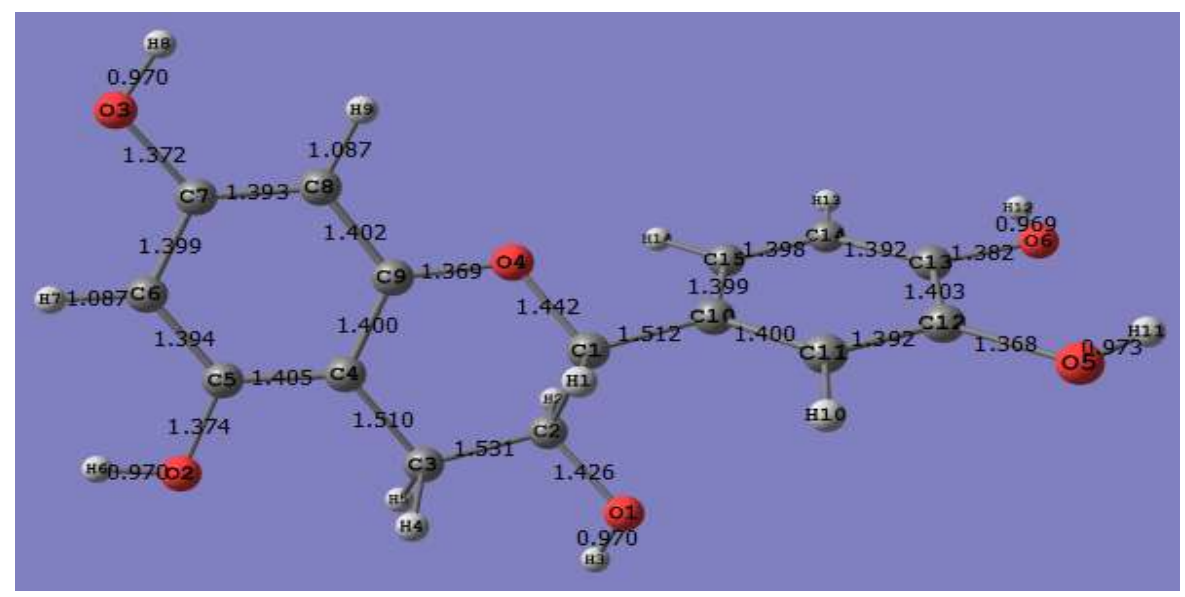

Figure 2: B3LYP /63+ G* optimized catechin structure.

The $\mathrm{C}-\mathrm{O}$ bond in the flavan ring is asymmetrical $\mathrm{C}_{1}-\mathrm{O}_{4}(1.442 \AA) ; \mathrm{C}_{9}-\mathrm{O}_{4}(1.369 \AA)$ owing to the effect of conjugation on the $\mathrm{C}_{9}$ side. The catechin molecule has a non-planar conformation given by the dihedral angles about $\mathrm{C}_{15} \mathrm{C}_{10} \mathrm{C}_{1} \mathrm{C}_{2}\left(78.9^{\circ}\right)$ and $\mathrm{O}_{4} \mathrm{C}_{1} \mathrm{C}_{10} \mathrm{C}_{11}\left(139.1^{\circ}\right)$. In addition the conformation of the heterocyclic is a halfchair the values of the torsion angles about $\mathrm{O}_{4} \mathrm{C}_{1} \mathrm{C}_{2} \mathrm{C}_{3}$ and $\mathrm{C}_{1} \mathrm{C}_{2} \mathrm{C}_{3} \mathrm{C}_{4}$ give evidence for such a conformation (Table 1). The four phenolic groups connected in two benzene rings can participate in the intermolecular hydrogen bonding formations. The selected bond lengths calculated at the B3LYP /631+ G* level of theory for the hydroxyls $\mathrm{O}-\mathrm{H}$ bonds in the phenyl groups are in good agreement with the experimental data with discrepancies under $1 \%$. 
The theoretical and experimental bond angles between carbon atoms present a difference about $2^{\circ}$, the presence of an oxygen atom diverted the experimental values around $3^{\circ}$ with respect to the theoretical bond angle, and the presence of $\mathrm{O}-\mathrm{H}$ group originates a great deviation of the angle in a range of $3-12^{\circ}$. The main difference in torsions angles is related to the vacuum phase considered for the catechin molecule in DFT calculations. From our calculations, it can be concluded that the geometrical parameters calculated at the B3LYP/ 6-31 + G* base set reproduce satisfactorily the experimental values for the catechin molecule.

Table 1: Selected intramolecular geometry for catechin compared with X-ray data taken from Ref [21].

\begin{tabular}{|l|c|c|}
\hline \multicolumn{1}{|c|}{ Parameters } & B3LYP/6-31+G* & Exp \\
\hline $\mathrm{C}_{13}-\mathrm{O}_{6}$ & 1.38 & 1.38 \\
\hline $\mathrm{C}_{12}-\mathrm{O}_{5}$ & 1.39 & 1.39 \\
\hline $\mathrm{C}_{7}-\mathrm{O}_{3}$ & 1.37 & 1.37 \\
\hline $\mathrm{C}_{5}-\mathrm{O}_{2}$ & 1.37 & 1.38 \\
\hline $\mathrm{C}_{2}-\mathrm{O}_{1}$ & 1.43 & 1.44 \\
\hline $\mathrm{C}_{15} \mathrm{C}_{10} \mathrm{C}_{1} \mathrm{C}_{2}$ & 78.9 & ---- \\
\hline $\mathrm{C}_{15} \mathrm{C}_{10} \mathrm{C}_{1} \mathrm{O}_{4}$ & -42.2 & ---- \\
\hline $\mathrm{C}_{2} \mathrm{C}_{1} \mathrm{C}_{10} \mathrm{C}_{11}$ & -99.8 & -87.0 \\
\hline $\mathrm{C} 1 \mathrm{C}_{2} \mathrm{C} 3 \mathrm{C} 4$ & 44.5 & 64.0 \\
\hline $\mathrm{O}_{4} \mathrm{C}_{1} \mathrm{C}_{10} \mathrm{C}_{11}$ & 139.1 & 152.0 \\
\hline $\mathrm{O}_{4} \mathrm{C}_{1} \mathrm{C}_{2} \mathrm{C}_{3}$ & -61.3 & -64.0 \\
\hline $\mathrm{C}_{1} \mathrm{C}_{2} \mathrm{C}_{3} \mathrm{C}_{4}$ & 44.5 & 47.0 \\
\hline $\mathrm{C}_{1} \mathrm{O}_{4} \mathrm{C}_{9}$ & 118.0 & 114.6 \\
\hline $\mathrm{O}_{4} \mathrm{C}_{1} \mathrm{C}_{11}$ & 107.5 & 105.3 \\
\hline $\mathrm{C}_{1} \mathrm{C}_{10} \mathrm{C}_{11}$ & 119.6 & 116.4 \\
\hline $\mathrm{C}_{1} \mathrm{O}_{4} \mathrm{C}_{9}$ & 118.0 & 114.6 \\
\hline
\end{tabular}

\section{2. pKa estimation}

The pKa values of the phenolic groups in catechin are calculated using PM6 method [16]. In this approach, the $\mathrm{pKa}$ is calculated using optimized $\mathrm{O}-\mathrm{H}$ bond lengths and partial atomic charges on the ionizable hydrogen atom [22]. Theoretical PM6 results (Figure.3) show that the most acidic phenolic groups are 3-OH and 3'-OH in the (B) ring with pKa values of 9.50 and 8.96 successively.<smiles>COc1cc(O[GaH])c2c(c1)OC(c1ccc(O[14CH3])c(O[14CH3])c1)C(O[14CH3])C2</smiles>

Figure 3: Theoretically PM6 predicted pKa values for neutral catechin.

The close acidity to these groups is a consequence of the symmetric structure characterized by an equivalence of positions 3 and $3^{\prime}$ ' 23]. The 4-OH in the (A) ring was the most acidic site, whereas the $3^{\prime}-\mathrm{OH}$ in the (B) ring. The slightest acidic site belongs to the successive groups 4'-OH and 2-OH with pKa values of 10.29 and 14.87. The catechin molecule exhibits competitive deprotonation between cycles (B) and (A) leading to a mixture of different mono phenolates. The $\mathrm{pKa}$ of the phenolic $\mathrm{O}-\mathrm{H}$ groups are very close and hydroxyls groups can be classified according to their acidity degree in the following order: 4-OH, 3'-OH, 3-OH, 4'-OH.

The calculated B3LYP /631+ G* Mulliken atomic charges populations of the catechin structure are shown in Figure 4. It is clear that negative charges are uniformly distributed over the oxygen atom of phenolic groups $\mathrm{O}-$ H. However cycle (B) connected with atoms O6 and O5 revealed the lower charge values $(-0.782$ and -0.687 respectively) than the cycle (A) ( -0.689 and -0.689 respectively), which could make them as preferred sites that undergo chemical reactions more easily, this also confirms that these sites are potential donors of protons. 


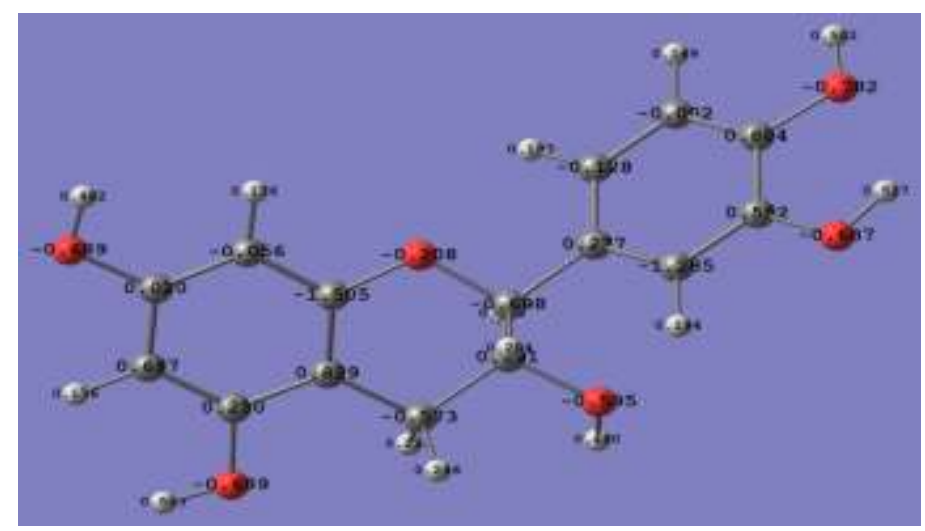

Figure 4: Mulliken atomic charges on various molecular moieties of catechin as deduced from their optimized B3LYP $/ 631+\mathrm{G}^{*}$ geometries.

The analysis of the atomic charge density distribution on the catechin surface (Figure 5) revealed the hydrophobic properties of the molecule with the presence of irrelevant hydrophilic areas, as evidenced by the resulting electrostatic potential showing negative and positive potential regions. The catechin molecule possesses many sites for electrophilic attack. The radical attack can be carried out on rings (A) or (B). Through ring (B), the catechin molecule could interact directly with nucleophilic compounds. Possibly, ring (B) reacts first during oxidation reactions $[24,25]$. It can be concluded regarding the reactivity of catechin molecule that ring (A) is the preferred site for electrophilic attack whereas ring (B) for nucleophilic attack.

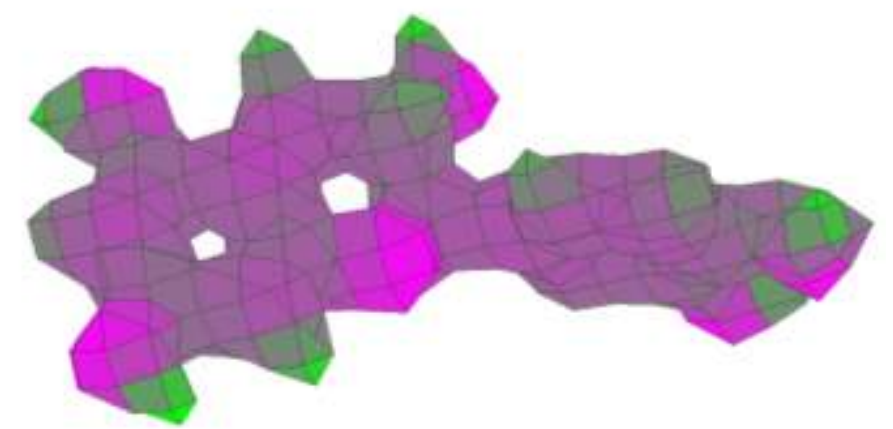

Figure 5: PM3 calculated electrostatic potential of catechin showing negative and positive potential regions.

\subsection{Bond order and bond length}

A previous study showed that the bond order and bond length of the phenolic hydroxyls $\mathrm{O}-\mathrm{H}$ can measure its strength to a certain extent. For smaller bond orders, the bond is weaker, the hydrogen can be removed more easily, and the phenolic hydroxyl is more active. Bond length also measures bond strength. Larger bond length corresponds to weaker bond, and therefore to smaller bond order [26, 27].

The results of the semi-empirical calculations AM1 of the bond order and the bond lengths of catechin are exposed in Table 2. The large values of bond lengths correspond to lower binding energy and therefore to less order of binding. Consequently, the values of bond order and bond length of catechin are opposed. The phenolic hydroxyls in cycle (B) may be the primary active sites of catechin because 3-OH and 3'-OH have the smallest bond order and largest bond length.

Table 2: Semi empirical AM1 calculated bond order and bond lengths for catechin molecule.

\begin{tabular}{|c|c|c|c|}
\hline Molecule & Phenolic groups & Bond order & Bond length $(\AA)$ \\
\hline \multirow{4}{*}{ Catechin } & 3-OH & 0.924 & 0.967 \\
\cline { 2 - 4 } & 3'-OH & 0.926 & 0.970 \\
\cline { 2 - 4 } & $2-\mathrm{OH}$ & 0.931 & 0.965 \\
\cline { 2 - 4 } & $4-\mathrm{OH}$ & 0.929 & 0.969 \\
\cline { 2 - 4 } & 4'-OH & 0.923 & 0.969 \\
\hline
\end{tabular}




\subsection{HOMO-LUMO charges distributions}

To understand the antioxidant activity in the context of molecular orbitals picture, we examined the molecular HOMOs (highest occupied molecular orbital) and molecular LUMOs (lowest unoccupied molecular orbital) generated via semi empirical PM3 calculation. The results for catechin molecule are summarized graphically in Figure 6.
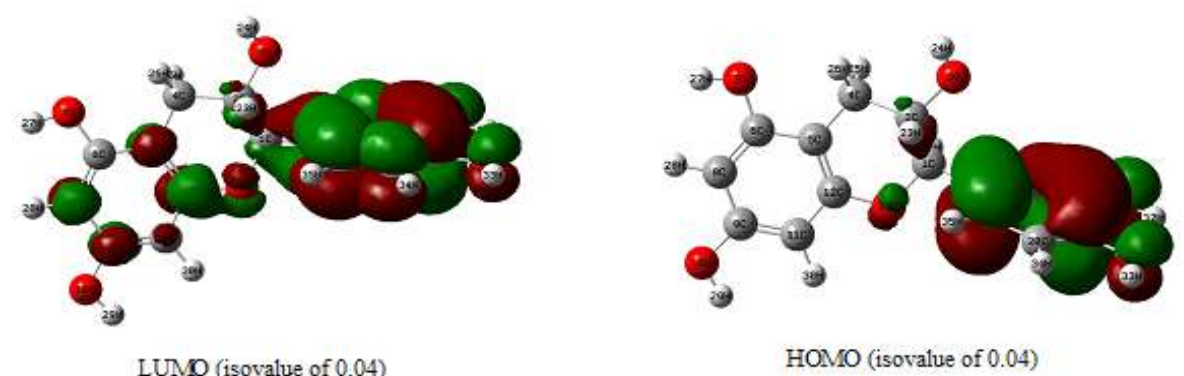

Figure 6: PM3 calculated molecular orbitals HOMO and LUMO of the catechin molecule.

Figure 6 shows that the HOMO and LUMO orbitals of the catechin molecule are located either on the catechol fragment or on the conjugated cycle (B).The LUMO was delocalized over the entire molecule indicating that the carbon atoms of ring (B) are potential sites for nucleophilic attack. The charges distribution of frontier orbitals also indicates that no electron transfer occurs between cycles A and B. These results are supported by the HOMO charge distribution, which represents the molecular negative charge density site. Its distribution is also observed on the carbon and oxygen atoms of ring B, indicating that these atoms are potential sites for electrophilic attack and the proton abstraction from the oxygen atoms requires a smaller energy than the energy of ionization equal to $8.82 \mathrm{eV}$.

\section{Quantitative structure-activity relationship}

Several semiempirical quantum chemical method studies have been conducted to establish the quantitative structure-activity relationship between catechins structure and their antioxidant activities [12, 28-30]. However, semi- empirical quantum chemical method PM7 (parameterized model 7) is a significant improvement and is much more precise than the previously used AM1 (Austin Model 1), PM3 and PM6 methods. The PM7 method is able to predict geometries and heat of formation consistent with DFT results and experimental observations [11-15]. In this part, semi-empirical PM7 calculations $[9,16]$ are carried out on tea catechins, allowing the investigation of relationships between antioxidant activity and catechins structures via the analysis of correlation curves. The calculations had surrounded multiple catechins parameters as: Heat of formation, HOMO-LUMO energies, bond dissociation energy and polar surface area (see Tables 3).

\subsection{Correlation of antioxidant activity (TEAC) and heat of formation $\left(\Delta_{f} H\right)$.}

VanAcker [26] considered that the difference in heat of formation $\Delta_{\mathrm{f}} \mathrm{H}$ between an antioxidant and its free phenolic radicals is the best parameter for predicting the antioxidant activity of catechins. The strength of the $\mathrm{O}-$ $\mathrm{H}$ bond in phenolic hydroxyl represents its ability to scavenge free radicals [12].The weaker the $\mathrm{O}-\mathrm{H}$ bond, the more active the antioxidant. Therefore, the difference of heat of formation index characterizing $\mathrm{O}-\mathrm{H}$ bond strength may be used as prediction parameters.

The values of the heat of formation of catechins molecules calculated by the semiempirical PM7 method are presented in Table 3. The order of stability established is as follows: (EGCG) $<$ (EGC) $<$ (ECG) $<$ (EC).

Tableau 3: Experimental TEAC and DPPH values, PM7 calculated minimal bond dissociation enthalpy, heat of formation $(\mathrm{kcal} / \mathrm{mol})$, HOMO-LUMO energies $(\mathrm{eV})$ and number of $\mathrm{OH}$ groups.

\begin{tabular}{|l|c|c|c|c|c|c|c|c|}
\hline Catechins & $\mathrm{n}(\mathrm{OH})$ & $\begin{array}{c}\text { TEAC } \\
(\mathrm{mM})^{\mathrm{a}}\end{array}$ & $\begin{array}{c}\mathrm{DPPH} \\
(\mu \mathrm{M})^{\mathrm{b}}\end{array}$ & $\begin{array}{c}\Delta_{\mathrm{d}} \mathrm{H} \\
(\mathrm{kcal} / \mathrm{mol})\end{array}$ & $\begin{array}{c}\Delta_{\mathrm{f}} \mathrm{H} \\
(\mathrm{kcal} / \mathrm{mol})\end{array}$ & $\begin{array}{c}\mathrm{E}_{\text {HOMO }} \\
(\mathrm{eV})\end{array}$ & $\begin{array}{c}\mathrm{E}_{\text {LUMO }} \\
(\mathrm{eV})\end{array}$ & $\begin{array}{c}\mathrm{E}_{\text {gap }} \\
(\mathrm{eV})\end{array}$ \\
\hline EC & 4 & 3.16 & 2.2 & 72.65 & -218.10 & -8.82 & -0.01 & -8.81 \\
\hline ECG & 5 & 3.86 & 1.1 & 72.74 & -261.61 & -8.94 & -0.10 & -8.84 \\
\hline EGC & 8 & 4.23 & 0.7 & 69.00 & -353.38 & -8.95 & -0.86 & -8.09 \\
\hline EGCG & 7 & 4.39 & 0.6 & 69.01 & -407.37 & -9.14 & -0.73 & -8.41 \\
\hline
\end{tabular}

${ }^{\mathrm{a}}$ Ref : [31]. DPPH ${ }^{\mathrm{b}}:$ [32]. 
A comparison of the heat of formation values of tea catechins with their antioxidant powers activities determined successively by the (DPPH) and the equivalent trolox (TEAC) $[31,32]$ let us to conclude that the higher the value of the heat formation the lower is its antioxidant activity. It is noted that the dominant antioxidant activity of the epigallocatechin gallate (EGCG) and Epigallocatechin (EGC) molecules is directly proportional to the number of hydroxyl groups $n(-\mathrm{OH})$ linked to ring (B) (Table 3). The increase in free radical scavenging capacity is strictly related to the number of hydroxyl groups in active ring (B).

The correlation plot between the experimental TEAC values and PM7 calculated heat of formation $\left(\Delta_{\mathrm{f}} \mathrm{H}\right)$ for catechins is shown in Figure 7.The reliable QSAR model developed using one set of experimental data is illustrated by Equation (1):

$$
T E A C_{\text {exp }}[m M]=2.062-0.006\left(\Delta_{f} H_{\text {theo }}\right)
$$

\subsection{Correlation of antioxidant activity $(T E A C)$ and energy gap $\left(E_{g a p}\right)$}

The low linear correlation coefficient $(\mathrm{R}=0.73)$ obtained between the antioxidant activity (TEAC) and the LUMO-HOMO energy difference $\mathrm{E}_{\text {gap }}$ (Figure 8), suggests that the antioxidant activity of catechins do not depends on electron affinity $\left(A=-E_{L U M O}\right)$ and ionization potential $\left(I=-E_{\text {номо }}\right)$. The correlation plot between the experimental TEAC values and PM7 calculated HOMO-LUMO energy difference $\mathrm{E}_{\text {gap }}$ for catechins is shown in Figure 8. The reliable QSAR model developed is illustrated by Equation (2):

$$
T E A C_{\exp }[m M]=13.377-1.109\left(E_{\text {gaptheo }_{\text {the }}}\right)
$$

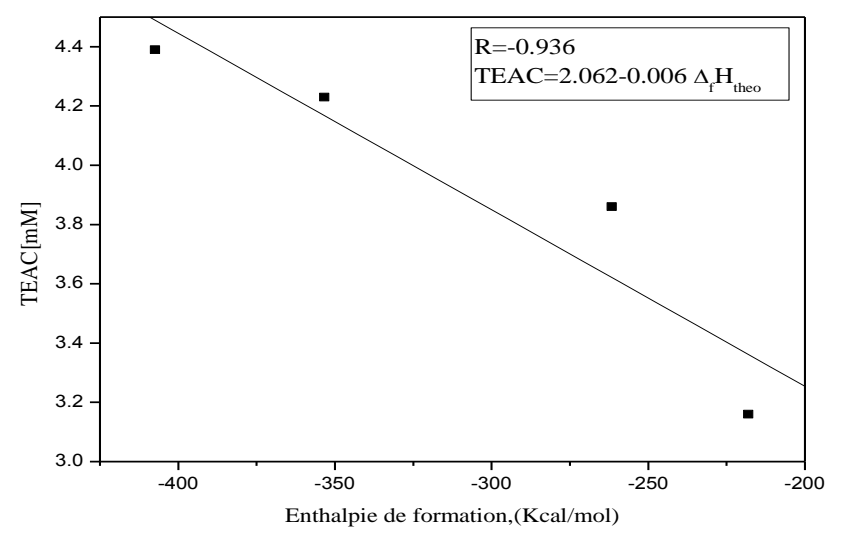

Figure 7: Correlation between experimental TEAC values and calculated $\Delta_{\mathrm{f}} \mathrm{H}$ for catechins

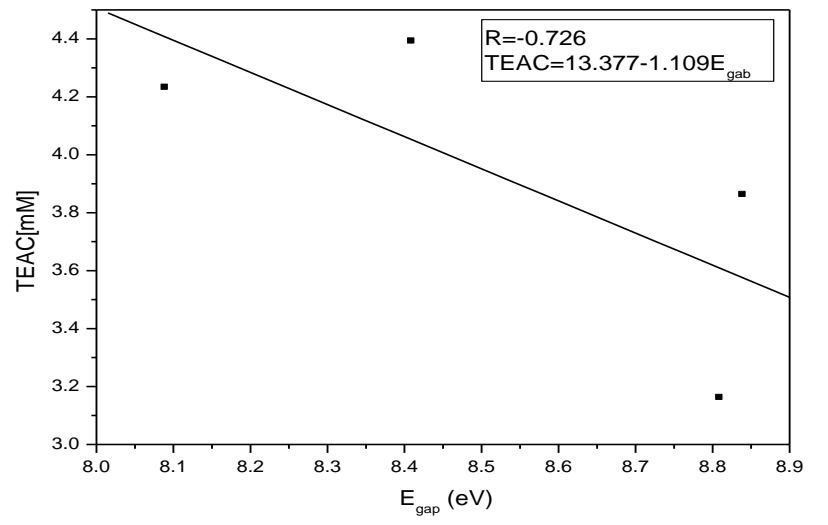

Figure 8: Correlation between experimental TEAC values and Egap of catechins.

\subsection{Correlation of antioxidant activity (TEAC) and polar surface area (PSA)}

The correlation plot between the experimental TEAC values and the calculated polar surface area (PSA) for catechins is shown in Figure 9. It is evident that the antioxidant activity of tea catechins is strongly associated with a great contribution of the polar surface area (PSA) parameter. The quality of this correlation is given by the high value of the correlation coefficient $\mathrm{R}=0.94$. The reliable QSAR model developed using one set of experimental data is illustrated by Equation (3):

$$
T E A C_{\text {exp }}[m M]=-116.60615+69.17677\left(P S A_{\text {theo }}\right)
$$

\subsection{Correlation of bond dissociation enthalpy $\left(\triangle_{d} H\right)$ and antioxidant activities (TEAC) /(DPPH)}

The ability of flavonoid antioxidants to donate a hydrogen atom is mainly governed by the $\mathrm{O}-\mathrm{H}$ bond dissociation enthalpy value. $[8,17]$. It has been established that the $\mathrm{O}-\mathrm{H}$ bond dissociation enthalpy is a useful molecular descriptor to predict the scavenging activities of some flavonoids against 2,2'-azinobis-(3ethylbenzothiazoline-6-sulfonic acid) radical [(ABTS•+ ), $\mathrm{TEAC}_{\mathrm{ABTS} \cdot+}$ assay] and 2,2-diphenyl-1-picrylhydrazyl radical [(DPPH•), DPPH assay] [33-35]. As can be seen from Table 3, the PM7 calculations identified the 4$\mathrm{OH}$ group of catechin as the group with lower bond dissociation enthalpy $\left(\Delta_{\mathrm{d}} \mathrm{H}\right)$. The correlation plot between the experimental antioxidant capacity TEAC and DPPH values and the calculated 4-OH bond dissociation enthalpies $\left(\Delta_{\mathrm{d}} \mathrm{H}\right)$ are shown in Figures (10a) and (10b) successively. 


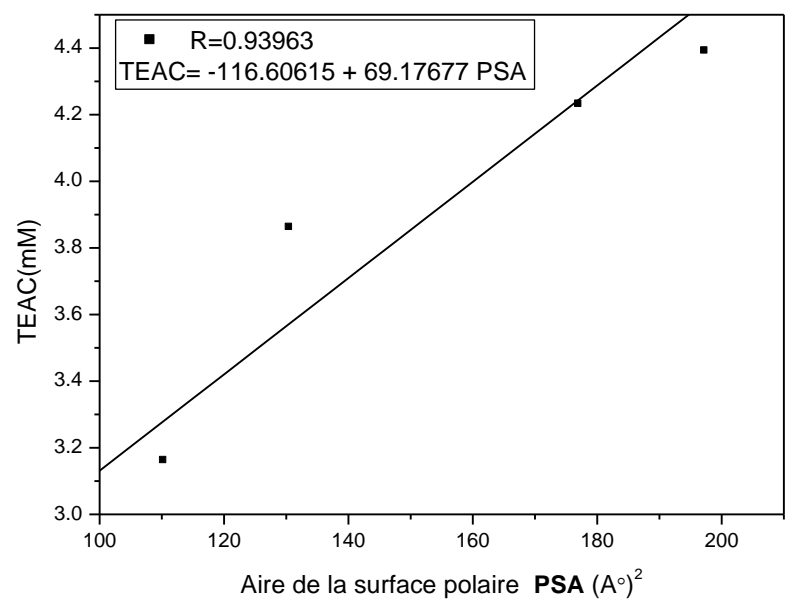

Figure 9: Correlation between experimental TEAC values and PSA of catechins.

Figures $10 \mathrm{a}$ and $10 \mathrm{~b}$ show an excellent linear relationship given by the high values of the correlation coefficients $(R=0.98$ and $R=0.95)$. It can be suggested that the enthalpy of binding dissociation is an excellent descriptor of antioxidant activity. The reliable QSAR models developed using the two sets of experimental data are illustrated by Equations (4) and (5):

$$
\begin{aligned}
& T E A C_{\exp }[m M]=53.48639-0.69367\left(\Delta_{d} H_{\text {theo }}\right) \\
& D P P H_{\text {exp }}[\mu M]=75.51576-1.11889\left(\Delta_{d} H_{\text {theo }}\right)
\end{aligned}
$$
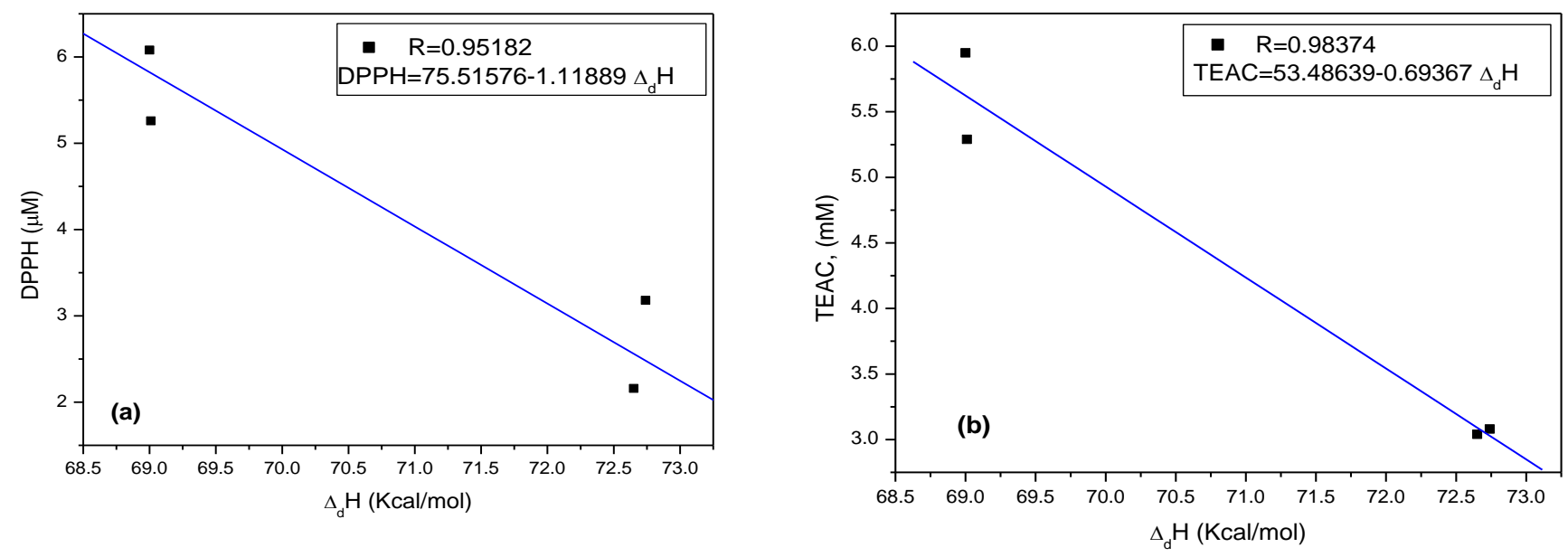

Figure 9: Correlation between tea catechins bond dissociation enthalpy $\left(\Delta_{d} H\right)$ and experimental antioxidant activity: (a) DPPH (b) TEAC.

\section{Conclusion}

Tea catechins are powerful natural antioxidants. The evolution of their structural, energetic and electronic properties has been undertaken by quantum chemistry calculations in order to understand their antioxidant activity and to find acceptable linearly formulation linking theoretical calculated parameters with experimental ones, the present study targets the following elements: (i) the calculation of geometric parameters (bond order, bond length and polar surface area), analysis of their contribution to the deprotonation of hydroxyl groups. This analysis is supplemented by complementary calculations as: pKa, heat of formation, bond dissociation enthalpy, HOMO-LUMO orbitals energy and electronic charge density. (ii) Correlation curves have been plotted and a reliable QSAR models developed using one sets of experimental data. The correlation coefficients calculated for this study are excellent and are defined in an interval varying from 0.94 to 0.98 .

Our results suggest that values of the cheaper calculations parameters: Heat of formation $\left(\Delta_{\mathrm{f}} \mathrm{H}\right)$, polar surface (PSA) and bond dissociation enthalpy $\left(\Delta_{\mathrm{d}} \mathrm{H}\right)$ can suitably scaled to predict the antioxidant activity of tea catechins. 
Acknowledgments- I gratefully acknowledge the support of this work by the Department of Materials Sciences, Tamanrasset University Centre in Algeria. N.S. Labidi thanks Prof. M. Hadjel from USTO-University.

\section{References}

1. J. Pérez-Jiménez, L. Fezeu, M. Touvier, N. Arnault, C. Manach, S. Hercberg, P. Galan, A. Scalbert, Am. J. Clin. Nutr. 93(2011)1220.

2. M.G. Ferruzzi, Physiol .Behav.100(2010)33.

3. M. E. Harbowy, D.A. Balentine, A. P. Davies, Y. Cai, Critical reviews in plant sciences. 16 (1997) 415.

4. M. Edeas, Phytothérapie. 5(2007)264.

5. J. P. Blaudeau, M. P. McGrath, L. A. Curtiss, L. Radom, J. Chem. Phys. 107 (1997) 5016.

6. V.A. Rassolov, M.A. Ratner, J.A. Pople, P.C. Redfern, L. A. Curtiss, J. Comput. Chem. 22 (2001) 976.

7. M. S. Gordon, Chem. Phys. Lett. 76 (1980) 163.

8. M.M. Francl, W.J. Pietro, W.J. Hehre, J.S. Binkley, D.J. DeFrees, J.A. Pople, M.S. Gordon, J. Chem. Phys. 77 (1982) 3654.

9. S. Karol., A. N. F. José Gomes, M.F. Manuel, J. Phys. Chem. A. 118 (2014) 9561.

10. S. Grimme, J. Antony, S., H. Krieg, J .Chem. Phys. 132 (2010) 154104.

11. H. Jirí, R. Jan, H. Pavel, Chem. Physics Letters .568 (2013) 161.

12. A. Dragan, L. Bono, Bioorganic \& Medicinal Chemistry. 18 (2010) 28.

13. Y. W. Yang, Q. Z. Feng, H. J. Xue, J. Mex. Chem. Soc. 58(2) (2014) 223.

14. J. Changho, H. Keum Taek, Int. J. Mol. Sci. 15 (2014) 14715-14727.

15. D. Amic, B. Lucic, Bioorg. Med. Chem. 18 (2010) 28.

16. J.J. Stewart, J. Mol. Model. 19 (2013) 1-32.

17. M. J. Frisch et al., Gaussian 09, Revision B. 01, Pittsburgh Gaussian. (2010).

18. J.J.P. Stewart, Computational Chemistry, MOPAC (2012).

19. HyperChem v8. Molecular Modelling System, Hypercube Inc., 1115 NW 4th Street, Gainesville, FL 32601, USA (2009).

20. ChemBio3D- Ultra, Perkin Elmer, Inc. All rights reserved (2014).

21. A.L. Spek, B. Kojic-Prodic, R.P. Labadie, Acta. Cryst. C40 (1984) 2068.

22. M.J.L. Munoz, M.F. Garcia, M.M. Garcia, J. Tudela, C. F. Garcia, L. J.N. Rodriguez, IUBMB Life. 61 (2009) 171.

23. N. P. Slabbert, Tetrahedron. 33 (1977) 821.

24. H.H. Hussain, G. Babia, T. Durst, J.S. Wright, M. Flueraru, A. Chichirau, L.L. Chepelev, J. Org. Chem. 68 (2003) 7023.

25. V. J. Olivero, L. L. Pacheco, J. Chem. Inf. Comput. Sci. 42 (2002) 1241.

26. S. A. B. E. Van Acker, D. J. Van den Berg, M. N. J. L. Tromp, D. H. Griffioen, W. P. Van Bennekom, W. J. F. Van Der Vijgh, A. Bast, Free Radical Biol. Med. 20 (1996) 331.

27. B.L. Zhao, S.L. Liu, R.S. Chen, W.J. Xin, Acta Pharm. Sin. 13 (1992) 9.

28. G. B. Rocha, R.O. Freire, A.M. Simas, J.J.P. Stewart, J. Comput. Chem. 27 (2006)1101.

29. J. J. P. Stewart, J. Mol. Model. 13 (2007) 1173.

30. T. Puzyn, N. Suzuki, M. Haranczyk, J. Rak, J. Chem. Inf. Model. 48 (2008) 1174.

31. Y. Z. Cai, M. Sun, J. Xing, Q. Luo, H. Corke, Life Sciences. 78 (2006) 2872.

32. F. Nanjo, K. Goto, R.Seto, M. Suzuki, M. Sakai, Y. Hara, Free. Radical. Biology and Medicine, 21 (1996) 895.

33. K. Furuno, T. Akasako, N. Sugihara, Biological \& Pharmaceutical Bulletin. 25 (2002) 19.

34. Z. Markovic, D. Milenkovic, J. Dorovic, J. M. Dimitric Markovic, V. Stepanic, B. Lucič, D. Amic, Food. Chem. 134 (2012) 1754.

35. D. Zhang, Y. Liu, L. Chu, Y. Wei, D. Wang, S. Cai, F. Zhou, B. Ji, J. Phys. Chem. A. 117 (2013) 1784.

(2018) ; http://www.jmaterenvironsci.com 